\title{
Hydrogen breath test for diagnosis of lactose malabsorption: The importance of timing and the number of breath samples
}

\author{
Mauro Di Camillo MD, Vanessa Marinaro MD, Fiorenza Argnani MD, Tiziana Foglietta MD, Piero Vernia MD
}

\begin{abstract}
M Di Camillo, V Marinaro, F Argnani, T Foglietta, P Vernia. Hydrogen breath test for diagnosis of lactose malabsorption: The importance of timing and the number of breath samples. Can J Gastroenterol 2006;20(4):265-268.
\end{abstract}

BACKGROUND: The hydrogen breath test $\left(\mathrm{H}_{2} \mathrm{BT}\right)$ is the most widely used procedure in the diagnostic workup of lactose malabsorption and lactose intolerance.

AIM: To establish whether a simplified two- or three-sample test may reduce time, costs and staff resources without reducing the sensitivity of the procedure.

PATIENTS AND METHODS: Data from 1112 patients (292 men, 820 women) with a positive $4 \mathrm{~h}$, nine-sample $\mathrm{H}_{2} \mathrm{BT}$ were retrospectively analyzed. Patients were stratified according to the degree of lactose malabsorption, the occurrence and type of symptoms. Loss of sensitivity in the procedure was evaluated taking into account two-sample tests $(0 \mathrm{~min}$ and $120 \mathrm{~min}$ or $0 \mathrm{~min}$ and $210 \mathrm{~min}$ ) or three-sample tests $(0 \mathrm{~min}, 120 \mathrm{~min}$ and $180 \mathrm{~min}$ or $0 \mathrm{~min}, 120 \mathrm{~min}$ and $210 \mathrm{~min}$ ).

RESULTS: Using a two-sample test $(0 \mathrm{~min}$ and $120 \mathrm{~min}$ or $0 \mathrm{~min}$ and $210 \mathrm{~min}$ ) the false-negative rate was $33.4 \%$ and $22.7 \%$, respectively. With a three-sample test ( $0 \mathrm{~min}, 120 \mathrm{~min}$ and $180 \mathrm{~min}$ or $0 \mathrm{~min}$, $120 \mathrm{~min}$ or $210 \mathrm{~min}$ ), lactose malabsorption was diagnosed in $91.2 \%$ (1014 of 1112) patients and in 96.1\% (1068 of 1112) patients, respectively. Of 594 patients with abdominal symptoms, 158 (26.6\%) and $73(12.2 \%)$ would have false-negative results with $0 \mathrm{~min}$ and $120 \mathrm{~min}$ or $0 \mathrm{~min}$ and $210 \mathrm{~min}$ two-sample tests, respectively. The three-sample tests, $0 \mathrm{~min}, 120 \mathrm{~min}$ and $180 \mathrm{~min}$ or $0 \mathrm{~min}, 120 \mathrm{~min}$ and $210 \mathrm{~min}$, have a false-negative rate of $5.9 \%$ and $2.1 \%$, respectively.

CONCLUSIONS: A three-sample $\mathrm{H}_{2} \mathrm{BT}$ is time- and cost-sparing without significant loss of sensitivity for the diagnosis both of lactose malabsorption and lactose intolerance.

Key Words: Hydrogen breath test; Lactose intolerance; Lactose malabsorption

T he genetically programmed reduction of intestinal lactase activity is responsible for lactose malabsorption (LM) in a large proportion of adults throughout the world (1), with the majority of susceptible individuals having developed lactase insufficiency by adolescence. However, LM is responsible for clinical symptoms (diarrhea, flatulence, bloating and abdominal pain) only in some patients and, therefore, the term lactose intolerance (LI) may be used only in these cases.

The prevalence of LM is high throughout the world, ranging from $50 \%$ to $70 \%$ in the normal Italian population

\section{L'épreuve respiratoire à l'hydrogène pour le diagnostic de la malabsorption du lactose : l'importance du moment des prélèvements et le nombre d'échantillons}

CONTEXTE : L'épreuve respiratoire à l'hydrogène est l'examen le plus utilisé pour le diagnostic de la malabsorption du lactose et de l'intolérance au lactose.

BUT : L'étude avait pour but de vérifier si une épreuve simplifiée à deux ou trois échantillons pouvait réduire le temps et le coût de réalisation et l'utilisation des ressources humaines sans diminuer pour autant la sensibilité de l'examen.

PATIENTS ET MÉTHODE : Nous avons procédé à une analyse rétrospective de données concernant 1112 patients (292 hommes, 820 femmes) qui ont obtenu des résultats positifs à une épreuve de $4 \mathrm{~h}$, comptant 9 échantillons. Les patients ont été divisés selon le degré de malabsorption du lactose, la fréquence des symptômes et leur type. La perte de sensibilité de l'examen a été évaluée par la prise de deux (0 min et $120 \mathrm{~min}$ ou $0 \mathrm{~min}$ et $210 \mathrm{~min}$ ) ou de trois échantillons ( $0 \mathrm{~min}, 120 \mathrm{~min}$ et $180 \mathrm{~min}$ ou $0 \mathrm{~min}, 120 \mathrm{~min}$ et $210 \mathrm{~min}$ ).

RÉSULTATS : Le taux de faux négatifs a atteint $33,4 \%$ et $22,7 \%$ respectivement pour l'épreuve à deux échantillons $(0 \mathrm{~min}$ et $120 \mathrm{~min}$ ou $0 \mathrm{~min}$ et $210 \mathrm{~min}$ ). Quant à l'épreuve à trois échantillons ( $0 \mathrm{~min}, 120 \mathrm{~min}$ et $180 \mathrm{~min}$ ou $0 \mathrm{~min}, 120 \mathrm{~min}$ et $210 \mathrm{~min}$ ), elle a permis le diagnostic de la malabsorption du lactose dans $91,2 \%$ (1014/1112) et 96,1 \% (1068/1112) des cas respectivement. Sur les 594 patients qui présentaient des symptômes abdominaux, $158(26,6 \%)$ et $73(12,2 \%)$ ont obtenu des résultats faux négatifs à l'épreuve à deux échantillons : 0 min et $120 \mathrm{~min}$, et $0 \mathrm{~min}$ et $210 \mathrm{~min}$ respectivement. Quant à l'épreuve à trois échantillons ( $0 \mathrm{~min}, 120 \mathrm{~min}$ et $180 \mathrm{~min}$ ou $0 \mathrm{~min}, 120 \mathrm{~min}$ et $210 \mathrm{~min}$ ), le taux de faux négatifs a atteint $5,9 \%$ et $2,1 \%$ respectivement.

CONCLUSIONS : L'épreuve à trois échantillons permet une réduction du temps et du coût de réalisation sans être accompagnée pour autant d'une perte importante de la sensibilité de l'examen en ce qui concerne le diagnostic de la malabsorption du lactose et de l'intolérance au lactose.

with a corresponding frequency in LI. Thus, ruling out LM and $\mathrm{LI}$ is important in patients with nonspecific abdominal pain.

The most widely used technique for the diagnosis of LM is the hydrogen breath test $\left(\mathrm{H}_{2} \mathrm{BT}\right)$, which is a simple, low-cost and noninvasive technique $(2,3)$. The increase in breath hydrogen excretion following an oral load of lactose implies malabsorption of the administered carbohydrate (LM). Various technical modifications of the procedure have been adopted to optimize the $\mathrm{H}_{2} \mathrm{BT}$ diagnosis of LM, namely by differing quantity of substrate ( $10 \mathrm{~g}, 25 \mathrm{~g}$ and $50 \mathrm{~g})$ (3), duration of the

Cattedra di Gastroenterologia I, Dipartimento di Scienze Cliniche, Universita di Roma, La Sapienza, Italy

Correspondence: Dr Piero Vernia, Dipartimento di Scienze Cliniche, Universita di Roma, La Sapienza, Policlinico Umberto I,

Viale del Policlinico 155, 00161 Rome, Italy. Telephone 39-06-49972360, fax 39-06-4463737, e-mail vernia@uniroma1.it

Received for publication August 5, 2005. Accepted September 7, 2005 


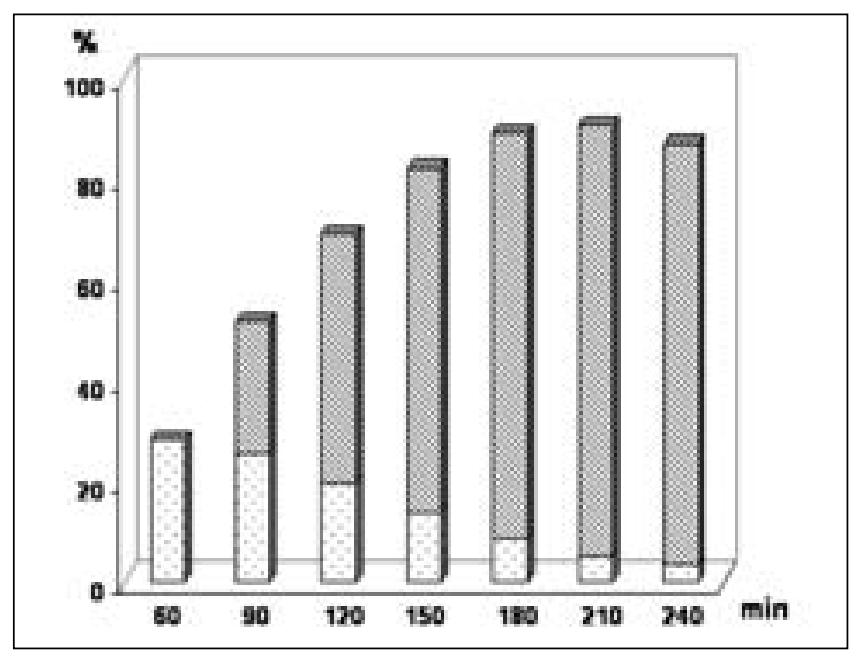

Figure 1) Occurrence of first peak of increased hydrogen concentration in alveolar air at various time intervals (dotted area) and overall prevalence of positivity (slashed area) in 1112 patients with lactose malabsorption

test (from $1 \mathrm{~h}$ to $8 \mathrm{~h}$ ) (4-6) and number of air samples (from three to nine samples with 30 min intervals) (7). Most recently, the use of new cut-off values (less than 6 parts per million [ppm] $6 \mathrm{~h}$ after the carbohydrate load, or a sum greater than $15 \mathrm{ppm}$ for the hydrogen values obtained $5 \mathrm{~h}, 6 \mathrm{~h}$ and $7 \mathrm{~h}$ after the carbohydrate load) improved the sensitivity of the test but implied a significant increase in the test duration (6). Nonetheless, in most laboratories, the duration of the $\mathrm{H}_{2} \mathrm{BT}$ is $4 \mathrm{~h}$, with endexpiratory breath samples collected every $30 \mathrm{~min}$ after the ingestion of $20 \mathrm{~g}$ to $25 \mathrm{~g}$ of lactose. Although the direct costs of $\mathrm{H}_{2} \mathrm{BT}$ are low, indirect costs are high due to the duration of the test, the prolonged involvement of qualified staff and use of infrastructure, as well as difficulties encountered in performing the test in more than six to eight patients at the same time. Due to these limits, the test is not suitable for LM or LI screening on a large scale. Therefore, some authors consider one single increase in hydrogen excretion to be positive, and have suggested reducing the overall test length and the number of samples to two (at $0 \mathrm{~min}$ and $120 \mathrm{~min}$ ), maintaining that the sensitivity of $\mathrm{H}_{2} \mathrm{BT}$ remains high $(7,8)$. The data, however, have not been confirmed by others $(9,10)$ because the two-sample $2 \mathrm{~h}$ procedure increases the false-negative rate and reduces sensitivity from $74 \%$ to $54 \%$, at least in adults $(11,12)$. On the other hand, the two-sample $2 \mathrm{~h}$ test is considered to be acceptable in pediatric patients, because infants and young children have a shorter mouth-to-cecum transit time compared with adults.

The present study, based on the retrospective analysis of data from 1112 patients with a positive lactose $\mathrm{H}_{2} \mathrm{BT}$, was aimed at evaluating whether a simplified two- or three-sample test and a duration of less then $4 \mathrm{~h}$ are suitable for reducing costs, time and staff involvement for the diagnosis of LM or LI in adults without a significant reduction in the sensitivity of the procedure.

\section{PATIENTS AND METHODS}

Between 1994 and 2004, 2256 consecutive adult patients referred to the Cattedra di Gastroenterologia I (Università di Roma, La Sapienza, Italy) undergoing the diagnostic workup for irritable bowel syndrome or with symptoms suggesting LM underwent a lactose $\mathrm{H}_{2} \mathrm{BT}$ following an oral load of sugar at a dose of $0.5 \mathrm{~g} / \mathrm{kg}$ body weight up to a maximum of $25 \mathrm{~g}$ (after a $24 \mathrm{~h}$ low-carbohydrate diet and a $12 \mathrm{~h}$ fasting period). End alveolar air samples were collected into syringes using a modified Haldane-Priestley tube, before the administration of lactose and every 30 min thereafter for $4 \mathrm{~h}$. Hydrogen concentration was measured in ppm by means of a Quintron Model DP Microlyzer gas chromatograph (Quintron Instruments, USA), with a detected accuracy of $\pm 2 \mathrm{ppm}$ and a linear response range of between $2 \mathrm{ppm}$ and $150 \mathrm{ppm}$. For the evaluation of the present series, the test was defined as 'positive' if a hydrogen peak exceeding baseline values by $20 \mathrm{ppm}$ was detected in two or more samples. The excretion of hydrogen was quantified as, the first peak of increased hydrogen excretion; the maximum peak of hydrogen concentration $\left(\mathrm{C}_{\max } \mathrm{H}_{2}\right)$; and the area under the curve of hydrogen concentration from $60 \mathrm{~min}$ to $240 \mathrm{~min}$ calculated with the triangular rule and expressed in arbitrary units of $\mathrm{ppm} / \mathrm{h}$.

Of 2256 patients, 1112 had a diagnosis of LM based on a traditional $4 \mathrm{~h}$, nine-sample $\mathrm{H}_{2} \mathrm{BT}$ and were considered to be eligible for the present retrospective study. The patient group was comprised of 292 men and 820 women, with a mean age of $37.7 \pm 14.9$ years. In the population, the loss of sensitivity of the test for diagnosing LM or LI was evaluated by taking into account only two samples ( $0 \mathrm{~min}$ and $120 \mathrm{~min}$ or $0 \mathrm{~min}$ and $210 \mathrm{~min}$ ) or three samples $(0 \mathrm{~min}, 120 \mathrm{~min}$ and $180 \mathrm{~min}$ or $0 \mathrm{~min}, 120 \mathrm{~min}$ and $210 \mathrm{~min}$ ).

Because symptoms occur more often in patients with high hydrogen excretion, the clinical impact of the loss of sensitivity was evaluated, stratifying patients according to the degree of LM and type of symptoms occurring in LI patients during the test and in the $4 \mathrm{~h}$ thereafter. For this purpose, patients with an excretion of hydrogen between $20 \mathrm{ppm}$ and $60 \mathrm{ppm}$ over baseline were arbitrarily classified as low-grade malabsorbers, while those in which the increase in hydrogen excretion exceeded $60 \mathrm{ppm}$ were classified as high-grade malabsorbers.

The inference between proportions was used for statistical analysis.

\section{RESULTS}

\section{Occurrence of first peak of increased hydrogen excretion}

The first peak of increased hydrogen excretion was observed at $60 \mathrm{~min}, 90 \mathrm{~min}$ and $120 \mathrm{~min}$ after the ingestion of lactose in $26.6 \%, 24.6 \%$ and $18.9 \%$ of patients, respectively. A progressively lower frequency of 'first excretion peaks' occurred in later phases of the test (Figure 1).

\section{Severity of LM}

High-grade malabsorption was detected in 622 patients (55.9\%). The mean excretion of hydrogen $\left(\mathrm{C}_{\mathrm{tot}} \mathrm{H}_{2}\right)$ was $101.52 \pm 40.62 \mathrm{ppm}$, while the mean value of $\mathrm{C}_{\max } \mathrm{H}_{2}$ was $100.76 \pm 30.99 \mathrm{ppm}$. Low-grade malabsorption was revealed in 490 patients $(44.1 \%)$. The mean $\mathrm{C}_{\text {tot }} \mathrm{H}_{2}$ was $44.99 \pm 17.09 \mathrm{ppm}$, while the mean $\mathrm{C}_{\max } \mathrm{H}_{2}$ was $46.88 \pm 11.27 \mathrm{ppm}$.

\section{LI}

Symptoms during the test occurred in 594 of 1112 patients (53.4\%): diarrhea in 103 patients (9.2\%), abdominal pain in 318 patients (28.6\%) and gaseousness in 504 patients (45.3\%).

\section{Simplified tests and diagnosis of LM}

Using a two-sample test ( $0 \mathrm{~min}$ and $120 \mathrm{~min}$ ), only 741 patients $(66.6 \%)$ emerged as malabsorbers. Somewhat better results 
could be obtained by sampling alveolar gas at 0 min and 210 min, because the diagnosis of LM was possible in 971 patients $(87.3 \%)$.

A three-sample test $(0 \mathrm{~min}, 120 \mathrm{~min}$ and $180 \mathrm{~min}$ ) further reduced the false-negative rate, leading to diagnosis of LM in 1014 of 1112 patients (91.2\%). The same held true for data collected with a slightly different three-sample test $(0 \mathrm{~min}$, $120 \mathrm{~min}$ and $210 \mathrm{~min}$ ), leading to correct LM diagnosis in 1068 of 1112 patients (96.1\%) of the original population.

\section{Simplified test and diagnosis of LI}

Of 594 patients with LI, 158 (26.6\%) and 73 (12.2\%) had falsenegative results with a two-sample test $-0 \mathrm{~min}$ and $120 \mathrm{~min}$ or $0 \mathrm{~min}$ and $210 \mathrm{~min}$, respectively. As expected, false-negative results were found mainly in those patients with a low production or excretion of gas (Table 1). Unfortunately, the false-negative results involved a large proportion of patients with clinically relevant symptoms such as diarrhea (23 patients with the 0 min and 120 min test and 13 patients with the 0 min and $210 \mathrm{~min}$ test). The three-sample tests $0 \mathrm{~min}, 120 \mathrm{~min}$ and $180 \mathrm{~min}$ or $0 \mathrm{~min}, 120 \mathrm{~min}$ and $210 \mathrm{~min}$, showed false-negative results in $35(5.9 \%)$ and $13(2.1 \%)$ patients, respectively. Only a minimum number of patients with diarrhea had a falsenegative test (six patients and one patient, respectively).

\section{DISCUSSION}

Although genetic testing may represent the ultimate tool for diagnosing lactase deficiency (13), the lactose $\mathrm{H}_{2} \mathrm{BT}$ is still the most widely used method for diagnosing LM and LI, despite an intrinsic loss of sensitivity related to the $5 \%$ to $7 \%$ of patients whose colonic flora does not produce detectable amounts of hydrogen. The main drawback to the widespread use of $\mathrm{H}_{2} \mathrm{BT}$ in clinical practice concerns the duration of the test, usually from $4 \mathrm{~h}$ to $8 \mathrm{~h}(4,5,14)$. Moreover, the number of patients that can be submitted to the test at any one time is low, unless the air sampling is performed directly by the patient and the samples are collected in air-tight plastic bags for subsequent analysis. All these factors, however, influence the direct and indirect costs of the procedure.

Results of the study show that a lactose $\mathrm{H}_{2} \mathrm{BT}$ can be effectively performed with only three breath samples, instead of the nine samples required in the traditional technique, and without a relevant loss of sensitivity. In the present series, a three-sample test ( $0 \mathrm{~min}, 120 \mathrm{~min}$ and $180 \mathrm{~min}$ ) would lead to diagnosis in $91.2 \%$ of patients with LM and $94.1 \%$ with LI. Even better results (LM 96.1\% and LI 97.9\%) emerged with the collection of a fourth sample at $210 \mathrm{~min}$. It remains to be established whether the slight increase in sensitivity justifies the longer duration of the test.

On the other hand, when the duration of the test is reduced to less than $3 \mathrm{~h}$ or the number of samples is limited to two, as suggested by some authors $(7,8)$, the sensitivity of the test drops to an unacceptably low level (about 70\%). Moreover, the main advantage of a three-sample test does not simply reside in a $30 \mathrm{~min}$ to 60 min reduction in the overall duration of the test. Because air collection and immediate analysis requires $3 \mathrm{~min}$ to $5 \mathrm{~min}$ per sample, the three-sample $\mathrm{H}_{2} \mathrm{BT}$ allows the processing of three separate groups of six to eight patients at the same time, with the second patient group beginning the test $30 \mathrm{~min}$ after the first patient group and the third patient group beginning 30 min later. We agree that a similar
TABLE 1

Mean values of hydrogen excretion in patients with positive tests and in those with false-negative results using various sample timing

\begin{tabular}{lcc}
\hline Time $(\mathbf{m i n})$ & $\begin{array}{c}\text { Positive tests } \\
\text { (ppm/h } \pm \text { SD) }\end{array}$ & $\begin{array}{c}\text { False-negative tests } \\
\text { (ppm/h } \pm \text { SD) }\end{array}$ \\
\hline 0,120 & $90.56 \pm 42.59$ & $43.19 \pm 18.46$ \\
0,210 & $80.78 \pm 45.66$ & $42.93 \pm 15.19$ \\
$0,120,180$ & $80.06 \pm 42.68$ & $29.13 \pm 9.16$ \\
$0,120,210$ & $77.52 \pm 43.08$ & $28.9 \pm 10.73$ \\
\hline
\end{tabular}

Low excretion of hydrogen is associated with false-negative results. ppm Parts per million

number of patients could be submitted to $\mathrm{H}_{2} \mathrm{BT}$ using air-tight bags filled directly by the patient. This procedure, however, is burdened by higher direct costs related to the use of disposable equipment and is hampered by a higher rate of sampling errors. Moreover, the loss of close interaction between patient and nurse or physician during the test may have a negative impact on the evaluation of the clinical relevance of symptoms. An alternative strategy is represented by the measurement of hydrogen concentration $6 \mathrm{~h}$ ( or $5 \mathrm{~h}, 6 \mathrm{~h}$ and $7 \mathrm{~h}$ ) after the ingestion of the lactose load, as suggested by Corazza and coworkers $(6,14)$. The authors' statement that this procedure may further improve the sensitivity of the test is debatable, as the occurrence of symptoms during the test has been considered suggestive for LM in the absence of a real gold standard. Because the patient population included a large proportion of patients with irritable bowel syndrome and functional bowel disorders, equating abdominal symptoms and LM may be misleading. Moreover, the near doubled duration of the test may indeed represent a problem for a wide diffusion of this technique in the clinical setting.

\section{CONCLUSION}

The present data suggest that a three-sample test $(0 \mathrm{~min}, 120 \mathrm{~min}$ and $180 \mathrm{~min}$ ) may lead to a threefold increase in the number of patients undergoing a $\mathrm{H}_{2} \mathrm{BT}$ without a relevant loss in sensitivity in the diagnosis both of LM and LI compared with the standard $4 \mathrm{~h}$, eight-sample test. This is true using $50 \mathrm{~g} \mathrm{(5)}$ or $25 \mathrm{~g}$ of lactose, which corresponds to a more usual intake of milk. The false-negative rate of lactose intolerant patients is low, but could be further reduced by $3.8 \%$ by collecting a fourth air sample at $210 \mathrm{~min}$, only in those patients with negative samples at $120 \mathrm{~min}$ and $180 \mathrm{~min}$, but complaining of abdominal symptoms during the test.

ACKNOWLEDGEMENTS: The authors are grateful to Marian Shields for help with English writing style.

\section{REFERENCES}

1. Friedl J. Lactase deficiency: Distribution, associated problems, and implications for nutritional policy. Ecol Food Nutr 1981;11:37-48.

2. Bozzani A, Penagini R, Velio P, et al. Lactose malabsorption and intolerance in Italians. Clinical implications. Dig Dis Sci 1986;31:1313-6.

3. Bond JH, Levitt MD. Quantitative measurement of lactose absorption. Gastroenterology 1976;70:1058-62.

4. Corazza GR, Sorge M, Strocchi A, Lattanzi MC, Benati G, Gasbarrini G. Methodology of the $\mathrm{H}_{2}$ breath test. Importance of the test duration for the diagnosis of carbohydrate malabsorption. Ital J Gastroenterol 1990;22:303-5.

5. Casellas F, Malagelada JR. Applicability of short hydrogen breath test for screening of lactose malabsorption. Dig Dis Sci 2003;48:1333-8. 
6. Di Stefano M, Missanelli A, Miceli E, Strocchi A, Corazza GR. Hydrogen breath test in the diagnosis of lactose malabsorption: Accuracy of new versus conventional criteria. J Lab Clin Med 2004;144:313-8.

7. Abramowitz A, Granot E, Tamir I, Deckelbaum RJ. Two-hour lactose breath hydrogen test. J Pediatr Gastroenterol Nutr 1986;5:130-3.

8. de Villiers FP. A standardized milk tolerance test. J Clin Gastroenterol 1987;9:320-3.

9. Brummer RJ, Karibe M, Stockbrugger RW. Lactose malabsorption. Optimalization of investigational methods. Scand J Gastroenterol Suppl 1993;200:65-9.

10. Robb TA, Davidson GP. Two-hour lactose breath hydrogen test. J Pediatr Gastroenterol Nutr 1987;6:481-2.
11. Koetse HA, Stellaard F, Bijleveld CMA, et al. Non-invasive detection of low-intestinal lactase activity in children by use of a combined ${ }^{13} \mathrm{CO}_{2} / \mathrm{H}_{2}$ breath test. Scand J Gastroenterol 1999;34:35-40.

12. Rosado JL, Solomons NW. Sensitivity and specificity of the hydrogen breath-analysis test for detecting malabsorption of physiological doses of lactose. Clin Chem 1983;29:545-8.

13. Swallow DM. Genetics of lactase persistence and lactose intolerance. Ann Rev Genet 2003;37:197-219.

14. Strocchi A, Corazza GR, Anania C, et al. Quality control study of $\mathrm{H}_{2}$ breath testing for the diagnosis of carbohydrate malabsorption in Italy. The "Tenue Club". Ital J Gasteroenterol Hepatol 1997;29:122-7. 


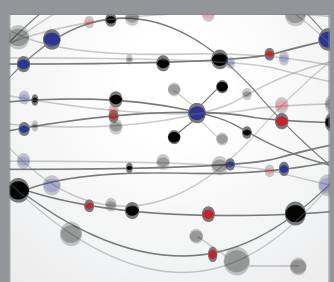

The Scientific World Journal
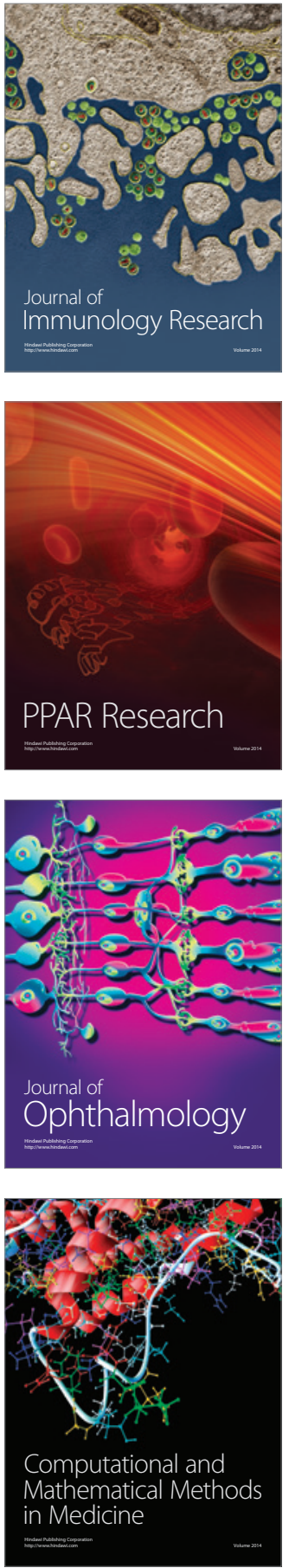

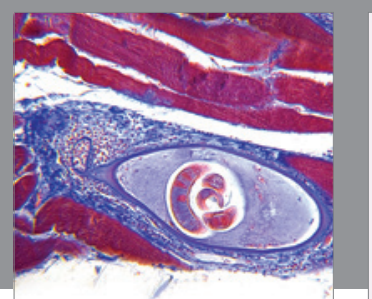

Gastroenterology Research and Practice

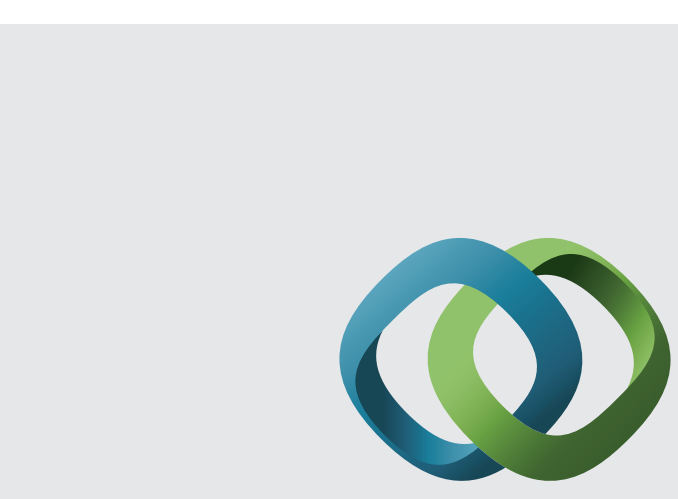

\section{Hindawi}

Submit your manuscripts at

http://www.hindawi.com
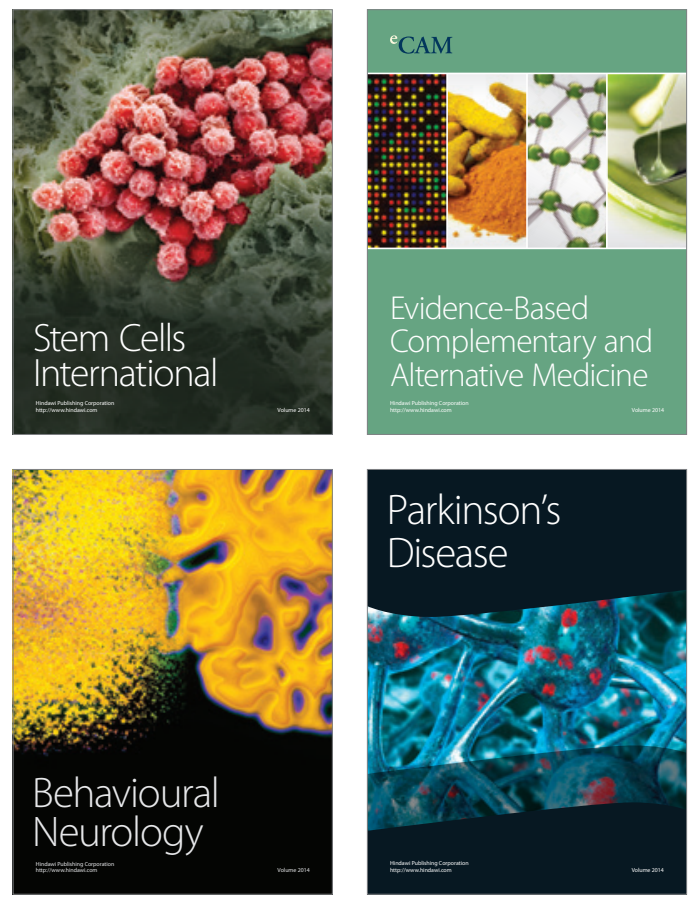
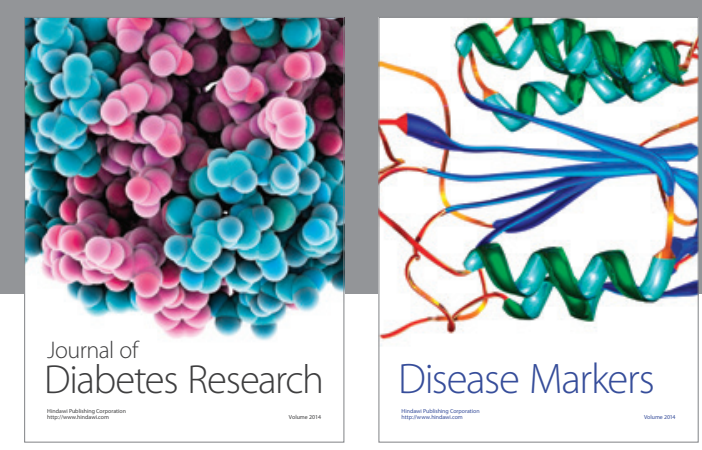

Disease Markers
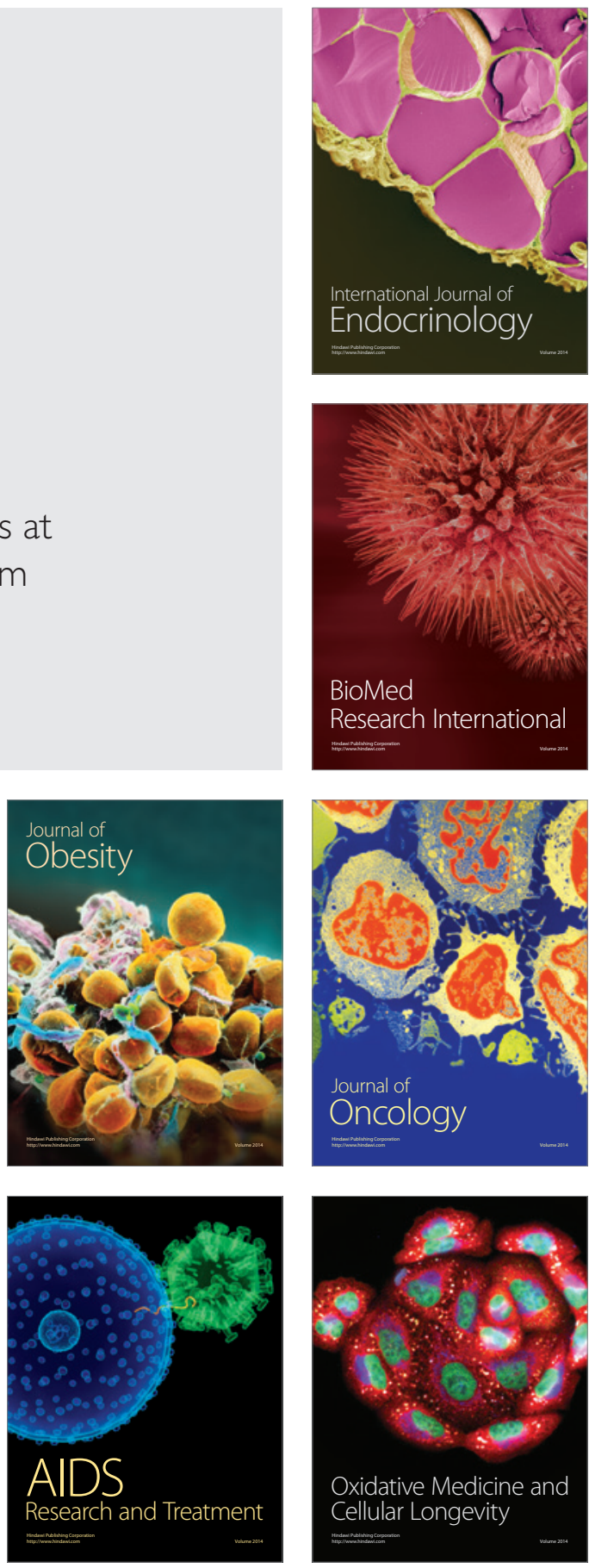